\title{
Holistic competence orientation in sustainability-related study programmes: lessons from implementing transdisciplinary student team research in Colombia, China, Mexico and Nicaragua
}

\author{
Álvaro Acevedo-Osorio ${ }^{1}$ (D) . Susanne Hofmann-Souki ${ }^{2} \cdot J_{\text {Juana Cruz Morales }}^{3}$
}

Received: 20 September 2018 / Accepted: 13 March 2019 / Published online: 25 March 2019

(c) The Author(s) 2019

\begin{abstract}
This article contributes with a tested transdisciplinary learning format to the discussion about strategies to increase regional relevance and competence orientation of higher education in the fields of sustainability and rural development. In the Latin American-European network "Rural Society, Economy and Natural Resources-Integrating Competence in Rural Development" (SERIDAR), scientists and practitioners in rural areas have jointly elaborated research problems, which were then investigated — among other formats—-by interdisciplinary teams of students within related study programmes. These projects had dual purposes: conveying essential professional competences to students and generating knowledge for and with participating rural actors. Linking approaches of transdisciplinary research and competence-oriented curriculum development, universities thus increased their efforts to fulfil their societal tasks and contribute to sustainable problem-solving. This article provides academic staff with insights into the didactic concept, tested and adapted in Mexico, Colombia, Nicaragua and China according to local conditions. Results of a comprehensive evaluation and systematisation process on local and international level are presented, as well as conclusions on factors and conditions necessary for the implementation and integration of transdisciplinary and problem-based student team research into university curricula as well as on this format as an element of collaboration for problem-solving in multi-stakeholder platforms.
\end{abstract}

Keywords Transdisciplinary education $\cdot$ Learning heuristics $\cdot$ Competence-oriented education $\cdot$ Systematisation

Sustainability-related problem-solving

Handled by: Patrick O'Farrell, Council for Scientific and Industrial Research South Africa, Africa.

Álvaro Acevedo-Osorio

aacevedoo@unal.edu.co

Susanne Hofmann-Souki

s.hofmann-souki@agrar.hu-berlin.de

Juana Cruz Morales

cruz_juanam@yahoo.com.mx

1 Faculty of Agrarian Sciences, National University of Colombia, Carrera 30 N 45-03, building 500 - Office 233, Bogotá, Colombia

2 Albrecht Daniel Thaer Institute for Agriculture and Horticulture, Division of Horticultural Economics, Faculty of Life Sciences, Humboldt-Universität zu Berlin, Unter den Linden 6, 10099 Berlin, Germany

3 Autonomous University of Chapingo, México, Street Diego de Mazariegos 85 Barrio La Merced, CP. 29240 San Cristóbal De Las Casas Chiapas, Mexico

\section{Introduction}

\section{The need for training complex problem-solving competencies in higher education}

Graduates of sustainability-related study programmes rely on their professional capacity to tackle complex problems in their field of work. It becomes apparent that this relates not only to the knowledge to be acquired, but particularly to methods, attitudes and practices to be mastered (Lacki 2003; Sarandón and Flores 2010). Hence, and this is the challenge, more holistic professionals need to be trainede.g. in sustainable rural development—with a pluralistic vision of food, production and socio-culture, with sensitivity regarding human and social problems of rural families and the capacity to understand and interrelate technical, economic and social issues (Lacki 2003) in the local and global context (Ramón 2010)—in short, complex problem-solving capabilities. 
They further require the deployment and co-development of different knowledge types: technical, empirical, scientific, practical, abstract and local (Nicolescu 1996; Morin 2007; Luengo 2012); systems knowledge, target knowledge and transformation knowledge are needed for analysing, developing and implementing (pathways to) new solutions (ProClim 1997).

Although study programmes have already taken up such competence needs in the formulation of their learning outcomes, we have observed that the learning activities (lectures, etc.) often do not yet match these ambitions and consequently fail to ensure that students are able to acquire the competences mentioned in the programme learning outcomes. It is obvious that developing this wide array of competences requires different didactic approaches, as described in Biggs and Tang (2011) and Wilhelm et al. (2015). Examples of such alternative formats include problem-based learning (Riseman et al. 2005), action and decision-oriented investigations (Fiege 2012), student involvement in university-industry partnerships (Larsson et al. 2009) and transdisciplinary case studies (e.g. Steiner and Posch 2006).

Many of them are based on experiential learning theory that defines learning as the process of creation of new knowledge through the transformation of a lived experience (Kolb 1984). The experiential learning cycle is also the didactic basis for problem-based learning (PBL) methodologies (see e.g. Barrett 2005). These aim at developing analytical and personal skills in students while generating thematic knowledge, using cases specifically designed to achieve pre-defined learning outcomes. Unlike common PBL practice whereby cases (problems) are prepared by lecturers alone (e.g. Jolliffe et al. 2005), the questions and problems developed within transdisciplinary educational formats are preferablyderived from a knowledge need of practitioners and aim at creating a concrete output for specific users who demanded the study (Hofmann-Souki et al. 2014a).

In this paper, we propose that transdisciplinary education may offer important contributions in particular for sustainable rural development studies and analyse the application of a transdisciplinary student team research format in four different countries.

\section{Learning processes in transdisciplinary research and education}

The term transdisciplinarity refers to joint problem-solving approaches by academics and practitioners within research processes which involve strong interaction, exchange and co-production of knowledge (Steiner and Posch 2006; Hollaender et al. 2008; Hadorn et al. 2008) aimed to contribute to both societal (Polk 2014) and scientific progress (Jahn et al. 2012). This involves interdisciplinary integration (i.e. integrating research of different disciplines) as well as science-practice interaction (Wright Morton et al. 2015).

Transdisciplinary learning involved in a transdisciplinary research process implies that ideally two parallel joint learning processes are created: a punctual learning process regarding the production of the research output as well as an overall learning process regarding the personal and joint capacity of all involved to do transdisciplinary research (Lang et al. 2012; Roux et al. 2017). Both learning processes follow the principle of iteration which implies that participants learn from reflecting on their experiences and then develop new concepts for action (and research), based on that reflection (Kolb 1984; Fortuin and van Koppen 2015). An explicit purpose in the development of a TdSTR project is to create, what Kolb and Kolb (2005) call an "educational learning environment" as a process that involves academic and community spaces in which the student generates not only knowledge, but also specific competencies to develop future transdisciplinary research projects.

This inherent learning focus also allows for integration of students into the process (Posch and Steiner 2006). While students - in particular PhD students-are often integrated in transdisciplinary research projects, they usually participate individually in research teams composed of a variety of actors.

We discuss in this paper an approach that explicitly addresses students to engage in planning, implementing and delivering transdisciplinary investigations as a team. We call this approach "Transdisciplinary Student Team Research" (TdSTR) - a learning format that may develop several of the necessary capacities mentioned at the beginning.

\section{Transdisciplinary student team research within the SERIDAR network: general features explained}

Seven universities in Mexico, Nicaragua, Costa Rica, Colombia, Ecuador, Spain and Germany have partnered in the EuropeAid-funded project "Rural Society, Economy and Natural Resources-Integrating Competences in Rural Development" (SERIDAR). It aims at increasing local relevance of university research and education through transdisciplinary networks in selected Latin American regions.

To bridge the gap between the academic and non-academic knowledge systems, university staff have integrated themselves into local stakeholder networks involving various types of actors such as farmers' groups, youth, peasant women, NGOs, GOs, and academics. Various research and education activities in SERIDAR hence follow a transdisciplinary approach, and one such type of education activity is TdSTR. For reasons of space, we concentrate on TdSTR in the remainder of this paper. 
The research problems and learning issues developed within the TdSTR approach are preferably derived from a knowledge need of practitioners - as elaborated in the local stakeholder networks mentioned above-and aim at creating a concrete output for specific users who demanded the study (Hofmann-Souki et al. 2014b). For most of the universities in the SERIDAR network, TdSTR projects constitute a new element in their study programmes and therefore are planned and implemented as pilot projects for testing purposes.

In the understanding that transdisciplinary research responds to local cultural, social and political conditions (Siew et al. 2016), each pilot project was designed specifically to the conditions of the region and participating actors. They follow two general purposes: (a) development of students' professional competencies in methodological-analytical, thematic as well as in social dimensions, and (b) to contribute with useful knowledge to and support joint learning in local stakeholders' development efforts.

The dual purpose of TdSTR implicates that objectives for the pilot projects are formulated on two levels: learning objectives for participating students, and research objectives for the investigation to be done. Based on these, learning activities need to be offered that ensure students are able to reach these objectives, as stipulated by Biggs and Tang (2011) regarding constructive alignment in teaching. This illustrates that students in these projects do not simply "run along" in a research project. The format is designed as an explicit educational activity that involves experiential learning in a team situation, and that places students centre stage in the investigation. These investigations form one of several elements of university engagement within a transdisciplinary network. The didactical concept and its foundations are further described in Hofmann-Souki et al. (2014b).

Figure 1 depicts the different steps and actors involved in TdSTR projects. The process and the learning cycles are shown in the academic, community or shared space where actors develop inter- or transdisciplinary work relations. The pilot projects generally include between 4 and 13 students, possibly from different study programmes, and are usually supervised by two or three lecturers of different disciplines. Practitioners as users of the outputs have an essential role in different project phases. Facilitated by the lecturers, the student groups plan and implement the projects, after clarifying with practitioner partners the purpose, the intended outputs as well as the use of the outputs. The students then elaborate the theoretical and analytical framework, plan and implement the methodology for obtaining and analysing the results (with a strong component of local users' participation), as well as present them in a way useful and applicable for the users and as required for university assessment. During their work, group members need to plan and act collectively and individually, communicate within an interdisciplinary and transdisciplinary context and reflect on the result elaboration and group processes that evolve (Hofmann-Souki et al. 2014b).

The role of lecturers is that of observers and facilitators of joint learning, in particular in conceptualisation and reflection phases. They ensure scientific quality of the work, appropriate communication with the stakeholders involved, spaces for reflection and feedback, and examination of those results which are included in student assessment. Some specific input is usually given mainly as methodological

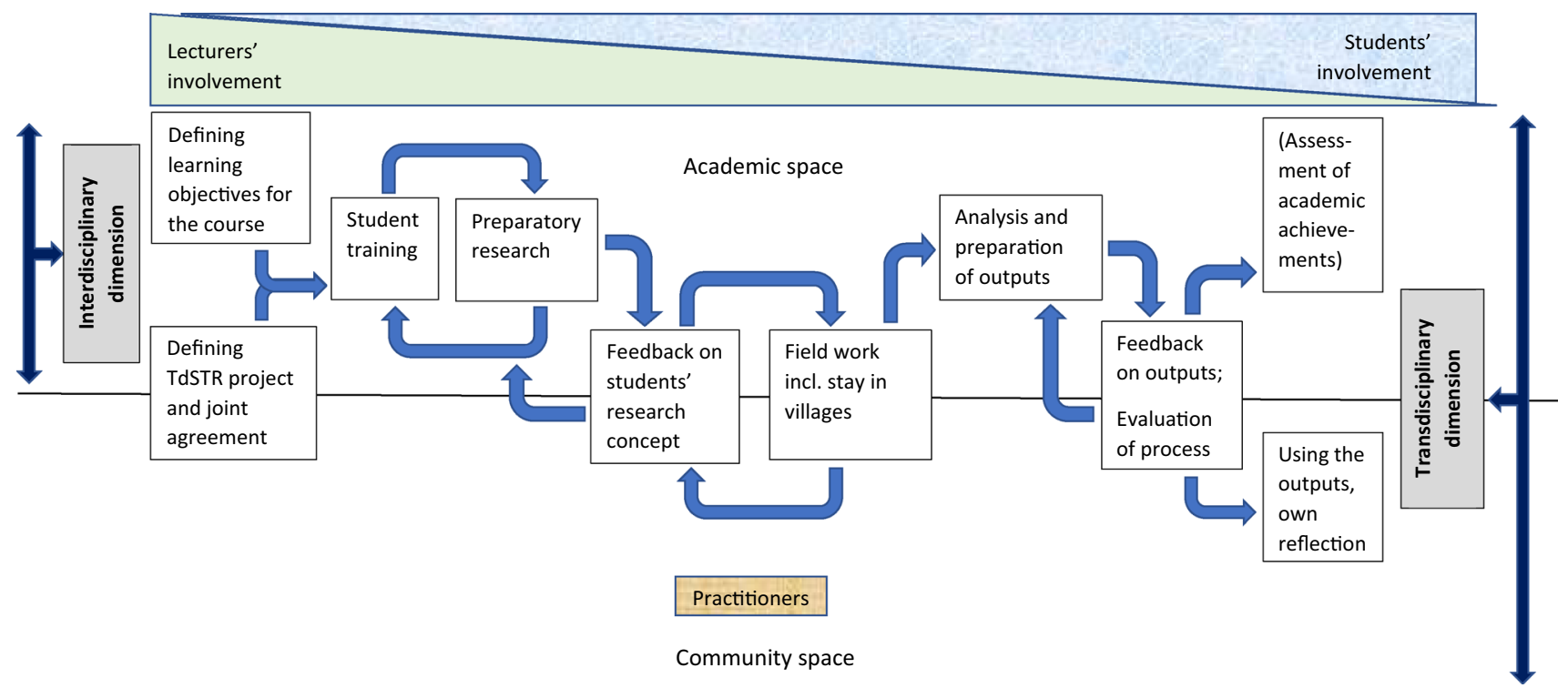

Fig. 1 Phases of the TdSTR projects in SERIDAR, actor involvement and learning cycles in inter- and transdisciplinary spaces 
trainings on research methodologies or teamwork techniques. In addition, the team of students and lecturers must establish trusting relationships with practitioners to guarantee a genuine understanding, a fluid communication and a constant and broad exchange between all participants during the development of the research.

The literature that shows transdisciplinary learning formats emphasises the need to confront students with the real world and its protagonists (Fortuin and van Koppen 2015). The contributions of Scholz et al. (2006), which proposes a theoretical framework that includes ontological, epistemological, methodological and organisational aspects that should be included in transdisciplinary training and research processes. Steiner and Posch (2006) developed a real case study for students to transcend the memorisation of concepts and live a learning experience more linked to the real world, concluding the need to strengthencreative, social and communication skills in students for this learning format. For their part, Fortuin and Bush (2010) analysed the development of skills in the interrelation between disciplines and cultures as well as between theory and practice in the development of a training course that allowed interdisciplinary work to overcome the bias of knowledge and get closer to practical solutions. In relation to these exposed cases, the TdSTR model puts students in direct contact with the reality of local actors to identify problems and design solutions related to rural development; likewise, it generates in the students the challenge to understand the local problematic and ask for scientific alternatives to provide solutions to real problems. The development of a specific training plan for students that integrates soft skills such as teamwork and communication with specific technical knowledge are necessary to face the real problem. The interface between scientific knowledge (interdisciplinary) and local knowledge (transdisciplinary) is an important feature in the format of the TdSTR through which both teachers and students cross, constantly trying to understand reality to contrast it with the theoretical positions of the scientific field (Fig. 1).

\section{Objectives and rationale of this paper}

The main objective of this article is therefore to contribute with a tested transdisciplinary learning format to the discussion and reflection on strategies to increase regional relevance and pedagogical fit of higher education in the fields of sustainability and rural development.

Departing from real-world problems in rural areas, the approach constitutes a proposal for aligning certain learning activities with the competences required by professionals in rural development and farming in their respective region. At the same time, it allows universities to deliver on its responsibility towards local communities and society, by endeavouring that research education address knowledge needs articulated by local stakeholders.

We have put forward a common overall didactic format, TdSTR, to be applied and tested at participating universities. It was to be expected that this test implementation would lead to adaptations, and that a comparison of the results and experiences made in the different universities/countries would yield valuable insights into the method's effectiveness as well as possibilities for its improvement. This may help faculty in the field of sustainability science and rural development to better answer the needs of students and of actors in rural development with whom they collaborate. Moreover, it may offer a model for integrating educational activities for students with ongoing or planned transdisciplinary research processes of faculty. In this article, we focus on cross-cutting didactical and methodological aspects of the TdSTR projects. We assume that those are of most interest to a wider public, in particular to faculty who consider introducing transdisciplinary learning formats into higher education curricula. Analysing thematic research outputs or the link between project characteristics and outputs is beyond the scope of this paper.

\section{Description of the pilot projects}

At its campus in Chiapas, the Autonomous University Chapingo (UACH) implemented the pilot project within its MSc in regional rural development (UACH-MCDRR). It included students having backgrounds in anthropology, veterinary medicine, animal breeding, sociology, tourism and informatics, furthermore two lecturers of rural development and a scientist of ecology, at the side of farmer families from five communities within the Biosphere Reserve La Sepultura in the Sierra de Villaflores, Chiapas. Research objectives were (1) the identification, through participatory analysis, of social water management practices-rules and agreements which the farmers have for water use and distribution; (2) establishing the status quo of water bodies as well as a critical path for water management for cattle raising in the mountains.

At the Institute of Agriculture and Horticulture of Humboldt-Universität zu Berlin (HU), Germany, the study project was planned as part of a transdisciplinary multi-stakeholder research project on sustainable rubber cultivation in southern China (SURUMER). This meant that part of the users of the research results were researchers themselves at Chinese and German universities. The other user of the results, Nabanhe Watershed National Nature Reserve (NRWNNR) Authority, was the main local collaborating partner, the nature reserve administration in the research region in Southern China. MSc student participants originated from the USA, Mexico, Malaysia, Germany and China, and they had different disciplinary backgrounds, 
under the supervision of lecturers from extension and communication science as well as agricultural economics divisions. The task was to perform a stakeholder analysis of rubber cultivation in the research area as a baseline study for further research activities within the larger SURUMER project. The research objective was to generate an understanding of the different stakeholder groups, their characteristics, communication networks, interests and problems perceived with relation to rubber cultivation in the Nature Reserve, as a basis for integrating stakeholder perspectives into further research activities.

The National University of Colombia (UN) formed an inter- and transdisciplinary team composed of students of sociology, political sciences, geography, agricultural engineering and agronomy as well as two professors of agricultural sciences. Together with farmers, they developed a participatory study project about the Irrigation District of Triángulo del Tolima, which is a large-scale irrigation scheme of the Ministry of Agriculture. The structure is being constructed in settlement zones of indigenous people and peasants and may put at risk the survival of these communities in case a mono-productivist plan is imposed and the various functions that the territory fulfils in the lives of these communities are not recognised and valued. The research objective was a joint understanding of the multifunctional characteristics of the communities' agricultural systems in the territory of the Guaguarco rivershed, highlighting the potentials and limitations for the planning of rural development programmes with a territorial focus for the district.

At the National Autonomous University of Nicaragua in Managua (UNAN-Managua), the project has been implemented in the semi-urban region Pochocuape. The research objectives included: (a) understanding the status quo of the water resource; (b) understanding the organisation of actors; (c) characterising the practices and tendencies of water use and their impact on production systems; (d) jointly elaborating alternative solutions that satisfy the water needs in the territory. Undergraduate students of economics and agricultural economics participated, as well as lecturers of agronomy, economics and residents of Pochocuape.

The characteristics of the four study projects are summarised in Table 1. Depending on the structure of the study programmes, projects were conducted in different formats, ranging from 6-week full-time to 9-month formats running in parallel to other courses. At UNAN and HU students received credits for participation, whereas at $\mathrm{UN}$ and $\mathrm{UACH}$ it was an activity additional to the regular courses of the programmes.

\section{Methodology}

The concepts of the pilot projects had been elaborated on the meta-level of the international working group in two joint workshops. The purpose of the pilot projects was to test the general TdSTR concept in regular academic educational practice. It had been clear from the beginning that after their implementation, the universities would need to decide whether or not to continue with such a type of learning activity within their curricula, and, if so, how to institutionalise and improve them. But how could we know how far the innovation was successful, so as to justify its institutionalisation? Beyond that, what can be learnt about transdisciplinary didactics in the field of sustainability and rural development? A methodological guide including an analytical framework was constructed to aid data collection and analysis on single project level and for cross-country synthesis.

The method selected for this meta-analysis is the systematisation (Chaves-Tafur 2006; Tapella and RodríguezBilella 2014; Jara Holliday 2012), focusing on analysing the experiences with TdSTR and on the process as a whole. It is not limited to the project logic itself, but rather allows to link several aspects and may include dimensions beyond an evaluation of mere project achievement. It promotes reflection, reconstruction and critical interpretation of experiences (Berdegué et al. 2007; Jara Holliday 2012) and thus helps to

Table 1 Main characteristics of the study projects analysed

\begin{tabular}{|c|c|c|c|c|c|}
\hline Institution & Project topic & Students & Lecturers & Local actors & $\begin{array}{l}\text { Position of the project within the train- } \\
\text { ing plan }\end{array}$ \\
\hline UACH-Mexico & $\begin{array}{l}\text { Water management for cattle raising in } \\
\text { the mountains }\end{array}$ & 6 & 2 & 75 & $\begin{array}{l}\text { Additional project under review to be } \\
\text { included in the master's programme in } \\
\text { regional rural development }\end{array}$ \\
\hline $\begin{array}{l}\text { HU-Germany and } \\
\text { China Agricultural } \\
\text { University }\end{array}$ & $\begin{array}{l}\text { Village Perspectives on Rubber Cul- } \\
\text { tivation }\end{array}$ & 13 & 4 & 55 & $\begin{array}{l}\text { Regular elective module named "Study } \\
\text { Project" in different MSc programmes }\end{array}$ \\
\hline UN-Colombia & $\begin{array}{l}\text { The multifunctionality of the irrigation } \\
\text { district El Triángulo del Tolima }\end{array}$ & 8 & 2 & 70 & $\begin{array}{l}\text { Additional project offered to students of } \\
\text { different university programmes }\end{array}$ \\
\hline UNAN_-Nicaragua & $\begin{array}{l}\text { Use and management of water in the } \\
\text { ecoforestry system }\end{array}$ & 5 & 4 & 65 & $\begin{array}{l}\text { Additional project to the training pro- } \\
\text { grammes developed in extra time of } \\
\text { students and teachers }\end{array}$ \\
\hline
\end{tabular}


achieve broader but systematic learning. The approach therefore offers an added value to the documentation and analysis of cases for joint learning as stipulated by Petry et al. (2011). Implementing pilot projects introduces a practical experience for the lecturers to learn from, and systematising these experiences offers a methodology for making the learning explicit and transparent.

Three basic phases are distinguished in the process, involving different actors in each step. Phase I started with a preparatory workshop. The key persons to be involved in the different phases were identified as well as the respective point of departure (initial situation at each university, context, and delimitation). The systematisation objectives and a list of criteria for analysing the experiences were developed. Based on the criteria and the publications of Chaves-Tafur (2006), Tapella and Rodríguez-Bilella (2014), UNDP (2011) as well as Jara Holliday (2012), a small team of participating lecturers elaborated a guide to the further joint systematisation process, including a set of guiding questions, related indicators and several tables for structuring data collection.

In Phase II, the involved practitioner partners, students and lecturers described and evaluated the development and results of each project: components, activities/actors, resources, results, achievements, difficulties encountered, unexpected results, opinions on future application and sustainability. It yielded mainly qualitative data at the level of each pilot project, collected through focus groups, interviews, and short anonymous questionnaires.

Analysis across countries was done in Phase III, starting with an international workshop of participating lecturers. Qualitative content analysis of systematisation documents followed. The results of an external evaluation of the overall SERIDAR project (Berlanga and Hernández 2014) served as additional input for data triangulation. In the cross-country analysis, we did not aim at a very systematic comparison of cases, as this would require a rather inflexible pre-defined approach. We focus on knowledge co-creation instead which allows joint sense making through discussion as well as recognition of unexpected developments. Based on the systematisation guide mentioned above and following Biggs and Tang (2011), Lang et al. (2012), as well as Yarime et al. (2012), an analytical framework was built which helped to analyse the learning achievements, compliance with transdisciplinary principles, as well as conditions and resources for implementation of TdSTR (Table 2). This aimed at creating a joint picture of central features that would make such a course a constructive element of curricula.

Part A of the table refers to the contribution of TdSTR to the pedagogical fit of the respective study programmes and addresses the learning achievements observed in our cases. Part B of the table refers to the contribution of TdSTR to the regional relevance of the study programmes, which is linked to the adherence of the pilot projects to transdisciplinary principles. Part $\mathrm{C}$ sheds light on the conditions and resources for implementing TdSTR; some of these aspects also offer explanations for certain difficulties encountered in achieving the above-mentioned curricular improvements.

\section{Results and discussion}

The framework in Table 2 forms the basic structure for describing and analysing systematisation results in this chapter.

\section{A: Learning achievements regarding thematic knowledge and methodological and social skills}

TdSTR was implemented with the aim of increasing pedagogical fit of existing study programmes with the professional competencies graduates should develop during their studies (see also sub-chapter C.1 below). Lecturers had formulated learning objectives for the students in three capacity dimensions:

- technical knowledge in specific issues for every pilot project (regarding water management and hillside livestock in UACH; sustainable management of soil and water in UNAL; stakeholder analysis for rubber cultivation in $\mathrm{HU}$; use of water in ecoforestry systems in UNAN),

- methodological competences (regarding participatory research; planning, execution and evaluation of research projects, complex analytical thinking), and

- social skills (regarding motivation and attitude, communication skills, teamwork).

Core learning achievements highlighted by students and observed by their lecturers include strongly increased transdisciplinary communication and teamwork skills at UACH, high learning achievement in teamwork and methodological-analytical skills at HU, capacity for group work, moderation techniques and interdisciplinary communication at $\mathrm{UN}$, in addition to commitment towards extension and joint learning with farmers; at UNAN the learning achievements on research methodology is highlighted.

In all cases students learnt to construct and apply concepts to analyse a complex problem situation. They stated more profound understanding of the research topic, its technical aspects and research methodologies in particular regarding its application in a real context. Lecturers observed that existing thematic knowledge was validated and broadened. Formulating research questions and constructing an analytical framework was learnt, too. After finalising the project students evaluated that they had made progress (which was also reflected in their subsequent MSc thesis projects, e.g. 
Table 2 Condensed framework for systematisation

Aspect of the systematisation
A: Learning achievements
A.1: Learning progress regarding thematic knowledge
A.2: Learning progress regarding methodological and research
capacities

A.2: Learning progress regarding methodological and research
Guiding questions

How far have participating students reached the defined learning objectives regarding conceptual and thematic knowledge on the topics covered in the project?

How far were participants able to integrate interdisciplinary knowledge?

How far have students acquired skills to plan, implement and evaluate a (small) research project?

How far have students acquired methodological and analytical skills necessary for doing research on complex real-world problems?

A.3: Learning progress regarding social skills necessary for transdisciplinary engagement

B: Adherence to transdisciplinary principles

B.1: Role of practitioners and collaboration within the project

B.2: TdSTR characteristics

B.3: Valoration by practitioners

C: Conditions and resources for implementation of TdSTR

C.1: Constructive alignment of learning objectives, learning activities and assessment

C.2: Need for and availability of resources for TdSTR

C.3: Institutional fit within study programmes and the university context
How far are project participants enabled to adequately handle inter- and transdisciplinary communication and teamwork?

How far has the project strengthened participants' commitment to engage in joint problem-solving processes in the rural sector?

How far have participating lecturers acquired necessary skills to facilitate TdSTR?

Have practitioner partners been involved in the definition of the research problem and objectives?

Has an agreement been reached regarding the objectives, expected results and distribution of responsibilities of academic and non-academic actors?

Has there been joint leadership of the process?

Have participants been able and committed to fulfil their different roles?

How far have practitioners participated in the evaluation of the projects?

Have ill-defined,societally relevant problems been tackled that contain challenging scientific questions?

Have collaborative research methodologies been used, including opportunities for joint sense making/integration and reflection?

Has both formal and experiential knowledge been taken up in the research?

How far have the results obtained been useful for gaining system knowledge and/or for problem-solving?

How far do participating non-academic actors value the process?

Have the learning objectives formulated been adequate for the study programmes and the TdSTR projects?

Have the learning activities and elements/environments been adequate for reaching the learning objectives?

Have assessment methods been suitable for the learning objectives and activities?

How far have central resources (time, finances, space) been available when needed?

How do the necessary resources invested relate to the outputs achieved?

How far are necessary resources expected to be available for continuing TdSTR?

How far do the universities enable and foster interdisciplinary and transdisciplinary activities?

How far does TdSTR fit within the different study programmes concerned?

Own elaboration based on Biggs and Tang (2011), Lang et al. (2012), Yarime et al. (2012) 
at $\mathrm{HU}$ ), but not all felt able to plan, implement and evaluate their own small research project.

Students at all universities also named empathic involvement with local stakeholders as a learning achievement, and in several cases students then had more motivation to do research and work with rural people and communities in the future. Students reported that they had gained tolerance as well as self-confidence to develop their abilities and to give and receive feedback on the collaboration process and results. Due to the participatory design, the students understood that they needed to assume a high degree of sensitivity and recognise the protagonist role of local partners; at the same time, they accepted the responsibility for their own learning in all dimensions.

Joint learning was possible if all participants, including lecturers, adopted a reflective attitude (Hollaender et al. 2008; Luengo 2012). This included joint construction of knowledge as students shared and discussed their research concepts and later on their findings with all participants. Practicing inter- and transdisciplinary communication became therefore a central feature in all pilot projects. Hearing the comments and suggestions made students reconsider some aspects of their concept, they learned to adapt it flexibly to the needs of stakeholders while maintaining scientific standards. Critical reflection and re-adjustments became more necessary during the empirical phase, of course. These reflexive and adaptive skills were also reported by Fortuin and van Koppen (2015) who conclude the need for careful planning of student training to achieve these skills that allow them to immerse themselves in situations that require the combination of both theoretical and practical knowledge.

Interestingly, students at $\mathrm{HU}$ evaluated that they profited little from the interdisciplinary composition of the team and some did not feel they could contribute with their own disciplinary background. Students at UACH found it very demanding to deal with other disciplinary perspectives. No specific didactic measures helped them to see an added value in these interdisciplinary differences - an aspect the lecturers would like to improve in the future. At UNAN, the composition of the research team remained disciplinary due to organisational limitations.

Evaluations at UNAN and HU also showed that learning progress varied largely due to the different previous experiences and personal ambition. The latter became a point of discussion at HU: How do we deal with the different expectations of students regarding the quality of the outputs? Lecturers noticed, however, that the intensive teamwork training and reflection prevented conflicts and minimised the common free-rider problem, as students became proficient in metacommunication.

Overall, analysis shows that achievements regarding methodological level and social skills are highlighted, as well as the lower transience that was given to specific thematic learning. This condition leads to reflect on the importance of TdSTR projects to achieve skills that other courses are not necessarily addressing but are crucial for the training of competent professionals, e.g. in the field of sustainable rural development.

\section{B: Adherence to transdisciplinary principles}

TdSTR was also designed with the purpose of improving regional relevance of the study programmes by addressing locally perceived problems through applied investigations, thereby placing students' learning within their direct societal context. For this reason, research objectives were formulated inclose collaboration with practitioners. In the Latin American cases, they were a result of discussions within the local networks into which supervisors had immersed themselves. In the case of $\mathrm{HU}$, the study project was a built-in part of a larger transdisciplinary research project that built upon an even longer-term relationship with local stakeholders in China, so that the research objectives were oriented towards serving the research team, feeding into the overall project's objectives.

Agreements with the practitioner partners were made in all cases, though differing in aspects and scope. In some cases (UACH, HU), the research concepts elaborated by the students were approved by the partners before the empirical research phase started. Besides the involvement of practitioners in data collection, results were discussed with them, so that they received an outside view on their situation. Final deliverables were agreed in accordance with their requirements (see e.g. Aenis et al. 2013). In most cases the practitioners were also involved in evaluation of the pilot project, both regarding results and process of the collaboration, as stipulated in Acevedo et al. (2013).

The aforementioned characteristics of the projects are in line with the principles of transdisciplinarity (Hadorn et al. 2008; Brandt et al. 2013). In such participatory projects, learning processes are developed both regarding the research topic and the collaboration (Hadorn et al. 2008, Groot and Maarleveld, 2000). However, as students were involved in these pilot projects, their learning advances constituted another layer in these processes.

Since the local knowledge represents one of the most important ways of knowing in systems of small-scale agriculture (Munyua and Stilwell 2013), it is relevant to highlight farmers' participation; nevertheless, they decided for themselves how intensively they may participate (Wang et al. 2018). Most importantly, they need to be able and willing to engage in the joint formulation of the problem, objective and expected results of the study (Elzinga 2008). At the case of UACH, one of the communities did not agree with the objectives of the other partners and consequently decided to withdraw. Whatever the decision of practitioner partners 
regarding the level of their participation, the research team needs to respect their readiness to do so. This resulted in diverse models of collaboration that in any case need to consider the capacities of local actors and users of the results (Wang et al. 2018). The latter, in turn, needed to accept that the study project has a second-educational—purpose, too, as stipulated by Fiege (2012).

According to the joint systematisation report, it was found important that the expectations of all involved were limited to the agreements and that no unachievable commitments were made-something that would create disappointments and a negative perception by the community of the research team and university collaboration. To limit the objective is perhaps the most important and difficult step; it was necessary to define the precise scope to align the expectations of the team with the existing possibilities of a study project. A challenge here was that the interdisciplinary composition of the student team-resulting from the logic of the study programmes - could not always be matched well with the respective research problem, and thus subsequent adjustments to the agreed outputs were necessary, e.g. at UNAN. A topic like stakeholder analysis (at HU) was easier to accommodate in a diverse team than more specialised research problems.

Due to the small scope of the pilot projects, limited resources and the small number of students engaged, there were no separate disciplinary subgroups investigating different aspects of the problem, and the outputs therefore did not lend itself to a full inter- and transdisciplinary synthesis as described, e.g. in Posch and Steiner (2006). Results helped to fill knowledge gaps and stimulated both the science-practice knowledge exchange and reflection within the communities, but—although implementation oriented-were mainly restricted to analysis, sketching possible solutions in some cases.

Regarding the use of the outputs generated in the pilot projects, a large majority of practitioners recognise that they have sufficient and quality information for future action plans; likewise they suggest to the universities that they continue with their work of accompaniment, generating new collaborative projects with the communities. This was confirmed in the external project evaluation (Berlanga and Hernández 2014). An additional indicator for this was the increased involvement of practitioners over time in the projects, e.g. at UNAN and HU. According to Ban et al. (2015), involving interdisciplinary groups of students opens up spaces for collaborative thinking beyond the path dependencies prevalent among established scholars.

A shared achievement of our TdSTR projects in Latin America was the strengthening of local networks (Berlanga and Hernández 2014) —not only with the universities but between local actors who now had a platform for exchange and collaboration. Similarly, other authors report that one of the most important results of university-community collaboration is its contribution to activate the work with local networks towards strengthening programmes on regional level (e.g. Bodorkós and Pataki 2009). It represents an important condition for ensuring that the activities of academic institutions on local level have an impact and a future perspective.

\section{C: Conditions and resources for implementing TdSTR}

\section{C.1: Constructive alignment of learning objectives, learning activities and assessment}

To support the achievement of intended learning outcomes (ILO) of the respective study programmes, the pilot projects should have learning objectives oriented towards these intended outcomes. Moreover, learning activities and assessment should be logically aligned and conducive (Biggs and Tang 2011). ILO of almost all study programmes involved (except the undergraduate programme in economics at UNAN) stress the development of an integrative and interdisciplinary understanding of problems in rural areas and sustainable development, critical analytical and research capabilities as well as aptitude for engaging in complex problem-solving, that is, a combination of theoretical, knowledge-related and application-oriented methodological skills as well as social competences. The learning objectives of the PP focussed on these three dimensions to different degrees: at UN there was a focus on applying participatory research methods, whereas UACH emphasised communication skills and the understanding of the local problem situation, and UNAN stressed the lifelong learning, motivation and problem-solving capacities. At HU, research and analytical skills, communication and teamwork, and lifelong learning capabilities were all addressed. This shows that acquisition of new thematic knowledge was not the main purpose of the projects. They aimed to contribute to the integration of disciplinary knowledge via the analysis of a certain complex sustainability problem, and mainly at developing methodological and social skills as mentioned in the ILOs. Several lecturers said afterwards they found it difficult to formulate suitable learning objectives that considered different levels of mastering certain competences (e.g. being able to name, explain, discuss, apply, perform something; see Biggs and Tang 2011).

Developing problem-oriented research objectives together with practitioners was also meant to specify and limit thematic and regional coverage. This experience is shared with transdisciplinary networks as described, e.g. in Larsson et al. (2009). Comparative studies, for example, would have been beyond the scope of a PP.

The research logic also shaped the learning activities and environment (see Fig. 1). Much of the learning took place "on the way" by actively going through the different 
stages in the project; spaces for reflection were purposefully created by faculty and mainly found useful by students. The most intensive learning experience in all cases was said to be the interaction with the local actors, which fostered a more holistic understanding of the problem and-above all-motivation and commitment. Other builtin sources of learning in SERIDAR pilot projects were:

- a mixture of disciplines in students' backgrounds and in approach to the research topic;

- role distribution between students and supervisors: students as decision makers;

- co-learning from peers;

- exposure to real-world situations like uncertainty over some aspects of the project's development

- living with rural families in the empiricalresearch phases.

Explicitly designed additional learning activities were training courses on participatory research methods at UNAN, UACH and UN as well as on teamwork techniques at HU (because of the larger group size). They were considered vital to ensure that students can work in a self-directed manner. This was subsequently confirmed by the majority of students and lecturers, but learning effects depended also on previous experience of students. Lecturers at HU and UACH noticed that the timing of these additional activities matters: students were unable to take up input before they arrived at the point in the project when that input really mattered. This effect is well known from problem-based learning (PBL) courses (Barrett 2005) and from learning theory: a person seeks to relate new input to existing knowledge or experiences.

As regards assessment, this was not yet an issue at the Latin American universities because the PPs were additional courses that were not graded. This resulted in some difficulties, e.g. at UN because students and staff had to prioritise their regular courses at the expense of the project at certain points. At HU, the project is a regular elective module with 12 credit points (EU ECTS system). Both oral presentation and final report were graded, i.e. the scientific output. In this way, thematic knowledge and methodological competences were assessed. However, assessment did not cover social learning. The project is considered a safe place for experimentation for students to try out new modes of behaviour and communication, without having to fear bad assessment in case of difficulties. Instead, the regular reflection loops allowed students to receive feedback from peers and lecturers, and plans for improvement were made and tested. A point of discussion was whether the report should be graded as a collective output-corresponding to the collective effort made-or according to individual parts, as stipulated by examination regulations.

\section{C.2: Need for and availability of resources for TdSTR}

Central resources necessary for TdSTR were said to be time of all participant groups, finance of logistics, and space for group activities. The latter was not named as a problem in any of the cases. Time, however, was seen as a major constraint. There were large differences between the cases regarding project length and intensity, as said above. So the first challenge for the faculty was to adjust the dimension of the project (and thus the research problem) to the curricular structure and student capacities. Difficulties became apparent in the shortage of time for literature analysis at UACH and $\mathrm{HU}$, for community engagement and report writing at UN. Aligning work rhythms of academics and practitioners added to this challenge.

Time invested by lecturers and practitioner partners was considered adequate for the projects in all cases. However, the Latin American lecturers would need the time invested to be credited for, to be able to integrate such activities in their regular portfolio. The problem is known at HU, too. However, the solution there is twofold: projects are preferably part of larger transdisciplinary projects and thus do not form extra activities. Also, the longer-term experience reduces the supervision time needed-lecturers know when students can be left to work by themselves and at which points their intervention is critical. In all cases at least two lecturers were (partially) engaged.

Financial resources were provided through third-party funding in all cases. The need for funding depended largely on the distance to the study sites and the rhythm of field research. At UACH, for example, students travelled to the villages several times-a half-day journey-and stayed there for several days. HU students had a 2.5 week field trip to China, with homestays at several villages in small groups. This made for a very dense time frame, and students had to contribute a certain part of travel costs. Acquiring and administering the necessary funding required considerable staff time and is thus a critical point for continuation of TdSTR, in particular if the project is not linked to other research and extension activities.

Another relevant resource was found to be the capacity of lecturers to supervise TdSTR, as previous experience varied. Lecturers proficient in their discipline are not always experienced in facilitating participatory research approaches, neither do they normally function as trainers of teamwork techniques. The challenge is known from the introduction of PBL into traditional curricula (Riseman et al. 2005). At UNAN, lecturers therefore conducted capacity-building workshops for their colleagues, whereas at $\mathrm{HU}$ it was tried to involve new lecturers into the projects as "training on the job", and specialists were invited for single sessions if needed. Staff fluctuation, however, threatens continuation of TdSTR, if the institutes are not committed to continuity 
of the format and the human resources required. Needless to say, aptitude and motivation of staff cannot be taken for granted, either. Participating lecturers, however, stated higher satisfaction with this type of work as compared to regular teaching.

\section{C.3: Institutional fit within study programmes and university context}

Integrating TdSTR as a learning format into several study programmes is the prerequisite for interdisciplinary composition of student teams. On MSc level, interdisciplinarity may also be achieved within a single programme by selecting students with different undergraduate degrees, as the experience at UACH showed. HU has made good experiences with ensuring interdisciplinarity also among staff involved as resource persons.

Transdisciplinary approaches to teaching and research are not widely accepted at any of the universities. We found that TdSTR would be much more efficient if it can build on existing transdisciplinary processes, structures and relationships with practitioner partners (Hofmann-Souki et al. 2014a). Existing networks and previous collaboration have helped in the case of UACH and $\mathrm{HU}$ to elicit meaningful research topics and eased communication. The week-long presence of the students in the communities, in turn, has strengthened the trust of the community members regarding the commitment of the university. So far, however, lecturers do not have institutional incentives to engage in transdisciplinary work and rely on personal commitment (see also Gibbs 2017).

Integration of TdSTR into study programmes means to make this learning a format part of students' curricula, assign credits and resources, and apply rules for grading. This is now tried at UACH in a new master's programme, whereas at UNAN it is contemplated as part of the curricular reform. At HU student team research has been an elective part of study programmes for some time, but permanent staff has not been assigned, so that the offer relies on motivated non-permanent staff. High commitment of the university to excellence in teaching and societal engagement is seen by participating lecturers as paramount to achieving the necessary institutional change.

\section{Lessons learnt and conclusions}

Transdisciplinary student team research represents a paradigm change in the conceptualisation of academic teaching and learning and offers new perspectives on problem-focused research activities with rural actors. The systematisation of the four TdSTR projects has shown that implementing such an approach is possible in an academic context that values holistic competence orientation, as is usually the case for sustainability-oriented study programmes.
For most of the universities concerned, TdSTR constituted an innovation to be tested and evaluated. University staff welcomed the possibility of linking their research with their education activities. Working on real-world problems was seen as a motivating factor, but the responsibilities and commitment were felt to rest on their shoulders, too. The engagement has created very positive expectations at the side of local partners, and it is a constant struggle to serve these expectations, both regarding results and process of collaboration, while having to adhere to university standards and procedures, too. As a result, the time and efforts of the supervisors dedicated to the projects were relatively high. This is reduced with more practice and better established working relationships.

The strength of TdSTR as a curricular activity is certainly its contribution to methodological and social learning outcomes of sustainability-related study programmes. They are not meant to replace discipline-based lectures that convey thematic knowledge, but rather support its application and contextualisation. Students see this as a crucial requirement for their professionalisation, and it is a known demand from practitioners (Hofmann-Souki et al. 2011). In this respect, we demonstrate that TdSTR has the potential to improving pedagogical fit of these curricula by increasing the learning achievements in competencies that are desired but often not yet addressed in traditional learning formats.

As regards the potential of TdSTR to improve regional relevance of higher education, the picture is a little mixed. The approach offers the chance for students and staff to better understand local problems of practice and places universities as collaborating actors in the problem-solving efforts of society. However, the scope, scale and depth of research need adjusting to the capacities of those involved. To have an impact theyshould therefore be an integral part of longerterm transdisciplinary processes.

Participation of practitioners in the definition of research problems and objectives is a key characteristic of transdisciplinarity and can be implemented in TdSTR more easily if such longer-term relationships exist. Formal collaboration agreements can be helpful if trust is yet to be established. Ideally, they follow an initial identification of expectations and capacities of all involved, assuring commitment and clarity of roles and expected achievements. Likewise, divulgation and joint discussion of project results is crucial for student learning and for maintaining long-term relationships with practitioners as the main users of the outputs generated. However, beyond the relationship with the communities and users of the research results, it is helpful to maintain a network of relationships with other organisations that could contribute directly or indirectly to the research (Muhar et al. 2006). Empirical work and participation of practitioners come at a cost. For pragmatic reasons, it is therefore helpful to concentrate activities on an easily manageable 
geographical radius (see also Larsson et al. 2009). Finding financial resources requires time and commitment as well-another argument for embedding TdSTR in research projects, so that the budget for empirical investigation and the transdisciplinary interaction with practitioners may be an integrated project activity.

As expected, several of the challenges encountered are shared with regular transdisciplinary research projects, in particular those challenges related to collaboration and to making impacts clearly visible (e.g. Brandt et al. 2013; Siew et al. 2016). Other challenges - those that relate to the establishment of transdisciplinary PBL team investigations within the study programmes - are known from PBL introduction phases at universities (Riseman et al. 2005; Hofmann-Souki et al. 2011; Ban et al. 2015), with the added transdisciplinary aspect. Specific challenges of the TdSTR projects are conflicts of interest, limited resources within teaching, as well as the balance between scientific demands and pragmatism (see also Fiege 2012).

Project teams have found different context-specific solutions for specific challenges that arose during project preparation and implementation. Effective solutions are identified more easily if faculty have immersed themselves in central paradigms of TdSTR. They need to be proficient in elaborating learning objectives adequate to the study programme and then plan-learning activities (including non-traditional ones) needed to reach these objectives. A challenge is the traceability of learning. It often cannot be pinned down to one specific activity like a certain training workshop, but results from a suitable composition and timely arrangement of elements and conditions. Supervisors need to be able to facilitate the evolvement of learning processes among students and with practitioners. The result is a process of joint reflection and continuous evaluation between lecturers, students (and practitioners) during the pilot project.

Given the challenges, finding lecturers willing and able to engage in TdSTR is therefore maybe the core bottleneck. It remains a big challenge in universities with research-oriented staff reward systems to introduce and reflect on complex teaching innovations in which application-related skills and know-how are consequently trained, and not only postulated as overall learning outcomes—often staff members (need to) have other career priorities. Furthermore, there are not necessarily any consequences in case curricula that do not allow students to attain the competences mentioned in the learning outcomes. For the study projects to gain momentum, it needs to be possible for staff to justify them with specific and binding learning outcomes to be served in each study programme. This requires universities' commitment to constructive alignment (Biggs and Tang 2011).

Crucial aspects to focus on are the institutional support from high-level staff members responsible for curricula as well as appropriate capacity building of faculty who supervise the projects. Students must be encouraged to assume shared responsibility for the learning and research process, together with practitioners and faculty. This in itself is motivating for all involved. However, our experience showed that awarding credits (study points) to students is important if such projects are integrated into the study programmes, so as to ensure that both students and faculty are able to dedicate sufficient time and attention to the projects. Overall, experience shows that incorporating TdSTR is more difficult within existing study programmes than during the development of new ones.

Nevertheless, the need for such change arises from new societal demands towards universities, as described at the beginning. Gibbs (2017) observes that higher education needs to find ways to tackle the complex concerns of society in the twenty-first century, or it might quickly lose its potency. In our classrooms we see that students are ready for the change. The pilot projects have taught us that TdSTR is a potential and rewarding step in this direction, with all the room for improvement.

Acknowledgements We offer our thanks to the teams of students who participated in the pilot projects in Colombia, Mexico, Nicaragua and Germany; to the groups of farmers in Colombia, Mexico, Nicaragua and China who allowed us to enter their communities; to Mario López and Jany Jarquín who shared their field work in Nicaragua; to the EU ALFA III programme for financing the activities of the SERIDAR project; finally, to the SERIDAR project team in Latin America and Europe for facilitating the pilot project process and systematisation of the methodology.

Open Access This article is distributed under the terms of the Creative Commons Attribution 4.0 International License (http://creativeco mmons.org/licenses/by/4.0/), which permits unrestricted use, distribution, and reproduction in any medium, provided you give appropriate credit to the original author(s) and the source, provide a link to the Creative Commons license, and indicate if changes were made.

\section{References}

Acevedo A, Ceciliano Y, Hofmann-Souki S, Jarquín Mejía J, Paredes Cauca M, Rojas J (2013) Guía para la sistematización de las experiencias y resultados del trabajo con los proyectos piloto. Internal working paper, SERIDAR project

Aenis T, Hofmann-Souki S, Nagel UJ, Tang L, Wang J (eds) (2013) Rubber cultivation and livelihood-a stakeholder analysis in Xishuangbanna, Southwest China. Humboldt-Universität zu Berlin, Berlin

Ban NC, Boyd E, Cox M, Meek CL, Schoon M, Villamayor-Tomas S (2015) Linking classroom learning and research to advance ideas about social-ecological resilience. Ecol Soc 20(3):35. https://doi. org/10.5751/ES-07517-200335

Barrett T (2005) Understanding problem-based learning. In: Barrett T, Mac Labhrainn I, Fallon H (eds) Handbook of enquiry \& problem based learning. CELT, Galway. http://www.nuigalway.ie/celt/ pblbook/. Accessed 16 April 2008 
Berdegué JA, Ocampo A, Escobar G (2007) Sistematización de Experiencias Locales de Desarrollo Rural. Guía Metodológica. Fidamerica y Preval, Santiago

Berlanga G, Hernández J (2014) Estado de avance de las actividades y resultados esperados: Proyecto SERIDAR. Evaluación externa Parte I. SERIDAR project -external evaluation report, Part 1. Puebla, Mexico

Biggs J, Tang C (2011) Teaching for quality learning at university. McGraw-Hill and Open University Press, Maidenhead

Bodorkós B, Pataki B (2009) Linking academic and local knowledge: community-based research and service learning for sustainable rural development in Hungary. J Clean Prod 17(12):1123-1131

Brandt P, Ernst A, Gralla F, Luederitz C, Lang DJ, Newig J, Reinert F, Abson DJ, von Wehrden H (2013) A review of transdisciplinary research in sustainability science. Ecol Econ 92:1-15

Chaves-Tafur J (2006) Aprender de la experiencia. Una metodología para la sistematización. Fundación ILEIA, Lima

Elzinga A (2008) Participation. In: Hadorn H et al (eds) Handbook of transdisciplinary research. Springer, New York

Fiege K (2012) Planung und Durchführung von Gutachten:Aktions und Entscheidungsorientierte Untersuchungen. In: Fiege K, Rauch T (eds) Entwicklungszusammenarbeit gestalten - Inhalte und Methoden für ein erfolgreiches Wirken in einem komplexen Berufsfeld. SLE publication series -S248. Seminar für Ländliche Entwicklung, Berlin

Fortuin KPJ, Bush SR (2010) Educating students to cross boundaries between disciplines and cultures and between theory and practice. Int J Sustain High Educ 11(1):19-35. https://doi. org/10.1108/14676371011010020

Fortuin KPJ, van Koppen K (2015) Teaching and learning reflexive skills in inter- and transdisciplinary research: a framework and its application in environmental science education. Environ Educ Res 22(5):697-716. https://doi.org/10.1080/13504 622.2015 .1054264

Gibbs P (2017) Transdisciplinary higher education. A theoretical basis revealed in practice. Springer, Cham

Groot AM, Maarleveld M (2000) Demystifying facilitation in participatory development. IIED Gatekeeper Series No. 89. http://pubs. iied.org/pdfs/X188IIED.pdf. Accessed 2 May 2017

Hadorn GH, Hoffmann-Riem H, Biber-Klemm S, GrossenbacherMansuy W, Joye D, Pohl C, Wiesmann U, Zemp E (eds) (2008) Handbook of transdisciplinary research. Springer, New York

Hofmann-Souki S, Pham VH, Tran TLH, Ashabul A (2011) Learning to teach learning - towards a concept for the training of lecturers in conducting problem-based learning study projects in Asia. Acta Hortic 920:45-53

Hofmann-Souki S. Acevedo-Osorio A, Bernal TC, Bokelmann B, Morales JC, López M, Yumbla MR (2014a) Establishing transdisciplinary research and learning environments for rural development-a network and process model. Paper presented at the 11th European IFSA Symposium, 1-4 April 2014. International Farming Systems Association, Berlin. http://ifsa.boku.ac.at/cms/filea dmin/Proceeding2014/WS_1_7_Hofmann-Souki.pdf. Accessed 11 June 2018

Hofmann-Souki S, Morales JC, Herrera R, Jarquín J, Cauca MP, Yumbla MR (2014b) Experiential learning in a transdisciplinary setting-learning from experiences in rural development studies. Paper presented at the 11th European IFSA Symposium, 1-4 April 2014 in Berlin, Germany, International Farming Systems Association. URL: http://ifsa.boku.ac.at/cms/fileadmin/Proceeding2014/ WS_1_5_Hofmann-Souki.pdf

Hollaender K, Loibl MC, Wilts A (2008) Management. In: Hadorn GH, Hoffmann-Riem S, Biber-Klemm W, Grossenbacher-Mansuy D, Joye C, Pohl U, Wiesmann U, Zemp E (eds) Handbook of transdisciplinary research. Springer, Berlin, pp 385-397
Jahn T, Bergmann M, Keil F (2012) Transdisciplinarity: between mainstreaming and marginalization. Ecol Econ 79:1-10. https://doi. org/10.1016/j.ecolecon.2012.04.017

Jara Holliday Ó (2012) Sistematización de experiencias, investigación y evaluación: aproximaciones desde tres ángulos. Int J Global Dev Educ Res 1:56-70

Jolliffe PA, Binns SE, Riseman AR (2005) Creating and implementing cases for problem-based learning in horticulture. Acta Hortic 672:161-170. https://doi.org/10.17660/actahortic.2005.672.18

Kolb DA (1984) Experiential learning: experience as the source of learning and development. Prentice Hall, Englewood Cliffs

Kolb AY, Kolb DA (2005) Learning styles and learning spaces: enhancing experiential learning in higher education. Acad Manag Learn Educ 4(2): 193-212

Lacki P (2003) La educación agrícola superior: la necesidad del cambio. FAO. http://www.actaf.co.cu/index.php?option=com_mtree \&task=att_download\&link_id=536\&cf_id=24. Accessed 23 Sept 2017

Lang DJ, Wiek A, Bergmann M, Stauffacher M, Martens P, Moll P, Swilling M, Thomas CJ (2012) Transdisciplinary research in sustainability science: practice, principles, and challenges. Sustain Sci 7(1):25-43

Larsson J, Ekelund L, Carlsson M (2009) Trends in the development of collaboration between horticultural research, education and industry. Acta Hortic 831:55-64

Luengo E (2012) La transdisciplina y sus desafíos a la universidad. Interdisciplina y transdisciplina: aportes desde la investigación y la intervención social universitaria. ITESO, Guadalajara

Morin E (2007) La cabeza bien puesta. Repensar la reforma. Nueva Vision, Buenos Aires

Muhar A, Vilsmaier U, Glanzer M, Freyer B (2006) Initiating transdisciplinarity in academic case study teaching: experiences from a regional development project in Salzburg, Austria. Int J Sustain High Educ 7(3):293-308. https://doi.org/10.1108/1467637061 0677856

Munyua HM, Stilwell C (2013) Three ways of knowing: agricultural knowledge systems of small-scale farmers in Africa with reference to Kenya. Libr Inf Sci Res 35:326-337. https://doi.org/10.1016/j. lisr.2013.04.005

Nicolescu B (1996) La Transdiciplinariedad: Manifiesto. Ediciones Du Rocher, Paris

Petry RA, Fadeeva Z, Fadeeva O et al (2011) Educating for sustainable production and consumption and sustainable livelihoods: learning from multi-stakeholder networks. Sustain Sci 6:83. https://doi. org/10.1007/s11625-010-0116-y

Polk M (2014) Achieving the promise of transdisciplinarity: a critical exploration of relationship between transdisciplinary research and societal problem solving. Sustain Sci 9:439-451. https://doi. org/10.1007/s11625-014-0247-7

Posch A, Steiner G (2006) Integrating research and teaching on innovation for sustainable development. Int J Sustain High Educ $7: 276-292$

ProClim (1997) Research on sustainability and global change-visions in science policy by Swiss researchers. CASS/SANW, Berna

Ramón JN (2010) Formación de competencias para salir de la pobreza en modelos educativos rurales. Consejo Latinoamericano de Ciencias Sociales, CLACSO, Argentina

Riseman A, Binns SE, Jolliffe PA (2005) Making the pedagogical transition to problem-based learning in a horticulture curriculum. Acta Hortic 672:35-45. https://doi.org/10.17660/ActaH ortic.2005.672.3

Roux DJ, Nel JL, Cundill G, O’Farrell P, Fabricius C (2017) Transdisciplinary research for systematic change: who to learn with, what to learn about and how to learn. Ssustain Sci. https://doi. org/10.1007/s11625-017-0446-0 
Sarandón S, Flores C (2010) Agroecología en escuelas agropecuarias de enseñanza media: el caso de la provincia de Buenos Aires, Argentina. Revista LEISA 26(4):27-29

Scholz R, Lang DJ, Wiek A, Walter AI, Stauffacher M (2006) Transdisciplinary case studies as a means of sustainability learning; historical framework and theory. Int J Sustain High Educ 7(3):226-251. https://doi.org/10.1108/14676370610677829

Siew TF, Aenis T, Spangenberg JH, Nauditt A, Döll P, Frank S, Ribbe L, Rodriguez-Labajos B, Rumbaur C, Settele J, Wang J (2016) Transdisciplinary research in support of land and water management in China and Southeast Asia: evaluation of four research projects. Sustain Sci 11(5):813-829. https://doi.org/10.1007/ s11625-016-0378-0

Steiner G, Posch A (2006) Higher education for sustainability by means of transdisciplinary case studies: an innovative approach for solving complex, real-world problems. J Clean Prod 14:877-890

Tapella E, Rodríguez-Bilella PD (2014) Sistematización de experiencias: una metodología para evaluar intervenciones de Desarrollo. Revista de evaluación de programas y Políticas Públicas 3:80-116

UNDP (2011) Systematization of knowledge transfer-methodological series on knowledge management, sharing knowledge for development projects. Knowledge Management Unit, UNDP Regional Centre for Latin America and the Caribbean. http://www.regio nalcentrelac-undp.org/images/stories/gestion_de_conocimien
to/Systematization \%20for\%20Knowledge \%20Transfer\%20-\%20 Methodological\%20Guide\%20v2013\%2003\%2021.pdf. Accessed December 2013

Wang J, Aenis T, Hofmann-Souki S (2018) Triangulation in participation: dynamic approaches for science-practice interaction in landuse decision making in rural China. Land Use Policy 72:364-371. https://doi.org/10.1016/j.landusepol.2017.12.066

Wilhelm SR, Förster U, Nagel G, Wülser Zingerli C (2015) Zukunft gestalten: Nachhaltigkeitskompetenzen in der Hochschulbildung. Gaia 24(1):70-72

Wright Morton L, Eigenbrode SD, Martin TA (2015) Architectures of adaptive integration in large collaborative projects. Ecol Soc 20(4):5. https://doi.org/10.5751/ES-07788-200405

Yarime M, Trencher G, Mino T, Scholz RW, Olsson L, Ness B, Frantzeskaki N, Rotmans J (2012) Establishing sustainability science in higher education institutions: towards an integration of academic development, institutionalization, and stakeholder collaborations. Sustain Sci 7(Supplement 1):101-113. https://doi.org/10.1007/ s11625-012-0157-5

Publisher's Note Springer Nature remains neutral with regard to jurisdictional claims in published maps and institutional affiliations. 